\title{
Research on the Design and Production of Online Course Video in the Age of Converged Media
}

\author{
Hanyue Zhang, Guili Zhang, Yinglong Yu \\ Southwest Petroleum University, Chengdu, China \\ Email:674243823@qq.com
}

How to cite this paper: Zhang, H. Y., Zhang, G. L., \& Yu, Y. L. (2020). Research on the Design and Production of Online Course Video in the Age of Converged Media. Open Journal of Social Sciences, 8 , 228-233.

https://doi.org/10.4236/jss.2020.811021

Received: November 3, 2020

Accepted: November 21, 2020

Published: November 24, 2020

Copyright $\odot 2020$ by author(s) and Scientific Research Publishing Inc. This work is licensed under the Creative Commons Attribution-NonCommercial International License (CC BY-NC 4.0). http://creativecommons.org/licenses/by-nc/4.0/

\begin{abstract}
Online course videos are the main carrier of online teaching. In order to improve the quality of online teaching and strengthen teachers' information literacy, this study summarizes the advantages of online courses based on the characteristics of the times and key points of teaching design. Meanwhile, this study discusses the transformation of teachers' mentality, analyzes the types of shooting suitable for online course videos in the era of integrated media, explores the design and specific production process of innovative online course videos, and provides references and suggestions for the majority of online teaching teachers.
\end{abstract}

\section{Keywords}

Integrated Media, Online Courses, Course Production, Course Design

\section{Introduction}

With the development of media technology and communication technology and its widespread use in the field of education, more and more teachers have participated in distance teaching. During the epidemic, teachers, trainers, experts, and scholars from educational institutions have all stepped onto the screen, teaching through video media, extending the classroom beyond the classroom and spreading it to everyone. In this sense, the ability to teach with camera lenses should be one of the basic qualities and abilities necessary for current or future teachers.

\section{Actively Respond to Changes in Education Informatization}

Twenty years ago, the "digital survival" storm set off by the Internet swept the 
world. At that time, many people were optimistically predicting that learning on computer screens would replace book learning and computers would replace teachers. At that time, politicians, parents and entrepreneurs gradually formed a strong desire: "Computers should enter school education, and vigorously promote computers and the Internet to enter the classroom" (Sang \& Xie, 2011).

\subsection{Changing the Concept of Informatization Teaching of Teachers}

In the context of the Internet era, the in-depth integration of information technology and education and teaching has become the general trend. Millennial students are called digital natives. They cannot adapt to the traditional teaching model based on scripts and call for reform of university teaching. The fundamental reason lies in the backwardness of learning and teaching concepts, the contradiction between scientific research and teaching, the obstacles of the evaluation system and the system, etc. Therefore, with the advent of the new trend of world education informatization and to promote the improvement of teaching quality, teachers need to persist in lifelong learning, and adapt to the changes of the times. At the same time, teachers continue to learn modern teaching techniques and use the advantages of the Internet to improve oneself.

\subsection{Advantages of Online Courses}

So what is so good about learning online courses? The four elements are indispensable. The value of Massive (large scale): to ensure timely feedback; there is always someone to speak; online but not talking is also rewarding. The value of Open: a strong learning atmosphere: all who come in want to learn; gather many opinions: the experience of different people will enrich the classroom content. The value of Online: flexible learning time and place: learning anytime and anywhere; self-paced and self-regulating learning: intelligent correction of the teaching platform. The value of Course: Only when you have a partner can you persist: mutual supervision; peer teaching: teach others to learn better by yourself.

\section{Common Forms of Online Courses}

Online courses are mainly based on teaching videos as the main carrier, which is a kind of contextualized curriculum format designed and developed by teachers for a certain subject knowledge (such as key points, difficulties, doubts, test points, etc.) or teaching link (such as learning activities, topics, experiments, tasks, etc.) (Song, 2019). There are four types of instructional video shooting, which are also the most common forms of instructional video shooting:

\subsection{Camera Shot}

The camera shot mainly uses camera equipment usually including mobile phones, cameras, camcorders, cameras and other equipment with video recording functions. It can record the whole process of the displayed micro-class teaching 
process. Whether using professional cameras or mobile devices, you can take self-shooting or invite students, teachers, professional companies etc, to assist in shooting.

Common methods of shooting: First, use video equipment to shoot. The production team can be invited to shoot with multiple cameras and multiple angles. The teaching videos are rich in format and not single. Second, use the mobile phone to shoot. Use the mobile phone holder, stand the mobile phone beside you, and record the teaching video of the portrait and power-point together. In addition, some teachers use the mobile phone + paper mode to shoot, and some use the mobile phone + blank paper + scene method, or the mobile phone + paper format for video shooting and so on. You can use your imagination and choose or innovate shooting modes to enhance the quality of online courses and learners' interest.

\subsection{Screen Recording}

As the name implies, the screen recording mode is to record the screen content through related software. With the help of screen recording software, the teacher's explanation and analysis of the knowledge points on the computer screen are recorded. Install screen recording software (such as Camtasia Studio, online screen recording network) in the computer, and record the teaching process presented in the form of power-point, word, drawing tool software, handwriting input software, etc.

\subsection{Software Synthesis}

Software synthesis is to use portrait, animation or video production software (such as Flash, Movie Maker, GIF Animator, etc.) to output instructional video clips using synthesis technology. Microsoft's Office 2010 version of Power Point can directly save the set courseware as a common video format, which greatly reduces the technical difficulty for teachers to develop videos (Cen \& Hu, 2013).

\subsection{Hybrid}

Hybrid refers to the use of various methods of production, editing, and synthesis in instructional videos. Video in this way requires a higher level of technical support and video editing. It takes more time, but the quality of the video (technical manifestation, learning support, etc.) will be higher.

\section{The Production Process of Online Courses}

Based on the characteristics and essence of online courses, we should think deeply about how to design an online course that students expect. Instructional video is the key to the production of online courses, and instructional design is an important factor affecting the quality of online courses.

Making a complete online course includes 9 steps, as shown in Figure 1. The first step: Course topic selection. The teaching team determines the content of 


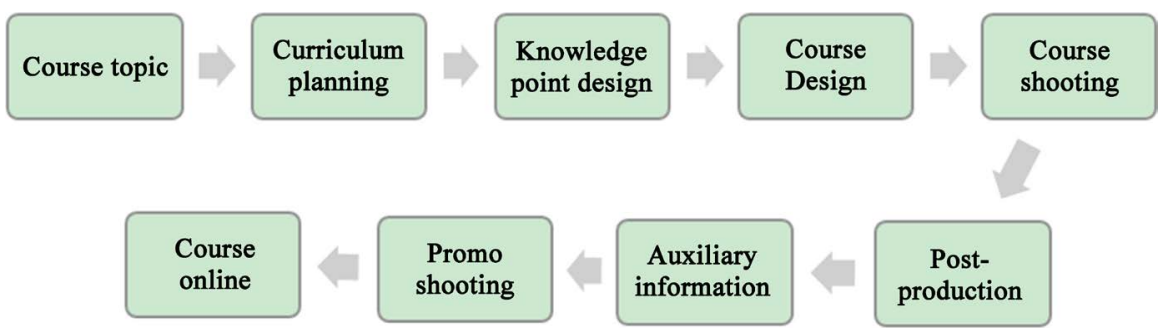

Figure 1. Online course production process.

the course that is more suitable for online teaching, and determines the key points, difficulties, doubts and hot spots of the course. Second step: Course planning. The teaching team and the production team jointly communicate the online course shooting form, video style and video presentation form, etc. The third step: Knowledge point design. The teaching team refines the knowledge point structure according to the curriculum plan, and organizes course chapters and other content. The fourth step: Course design, the teaching team communicates with the production team again, to refine the shooting method of each chapter, next to plans the shooting script of each shooting video, and provides technical support to complete high-quality online teaching courses. The fifth step: Course shooting, the production team will shoot video according to the requirements of the teaching team. The sixth step: Post-production. The production team edits and beautifies the video according to the communication details, and fully highlights the teaching content. The seventh step: Supplementary materials. Online courses cannot be taught by video alone. A large amount of auxiliary materials should also be provided for learners to carry out extracurricular learning. The eighth step: Shooting the promotional video. The production team plans and shoots the promotional video of the course according to the teaching team and course content. The ninth step: The course is online. The production team assists the teaching team to upload relevant teaching resources and start online teaching.

\section{Learn to Handle Scripts}

The shooting script is an indispensable preliminary preparation for creating a film. The script basically contains the name of the course, the lecturer, the type of lecture, the production staff, the shooting time, the shooting method, etc. And then the plan is divided into shots one by one. The main content of the shots includes target positioning, content design, preset time, lens performance, etc. After the shooting is completed, sort out the existing problems in the initial shooting. If necessary, you can redesign the script and shoot again to achieve the best teaching effect. The links of a complete teaching process design include introducing new courses, teaching new courses, experience discovery, expansion, classroom summary, etc.

For the network course structure design, two commonly used structures are recommended. First, the introduction-body-conclusion structure is shown in 


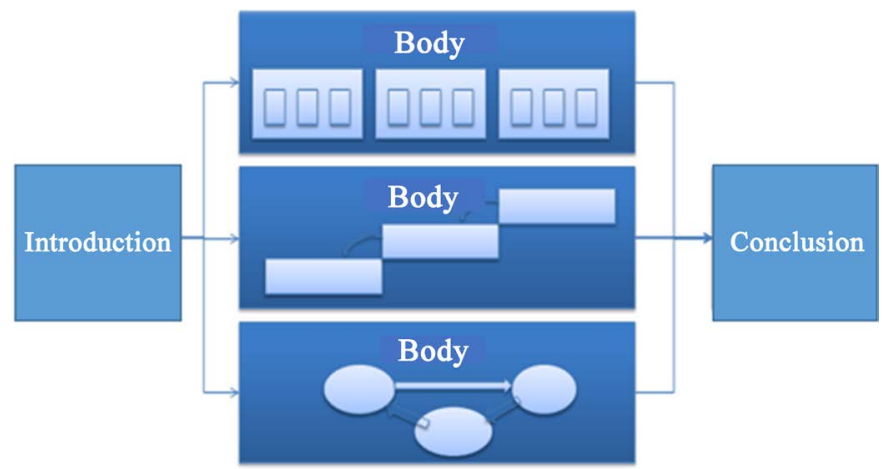

Figure 2. Introduction-body-conclusion structure.
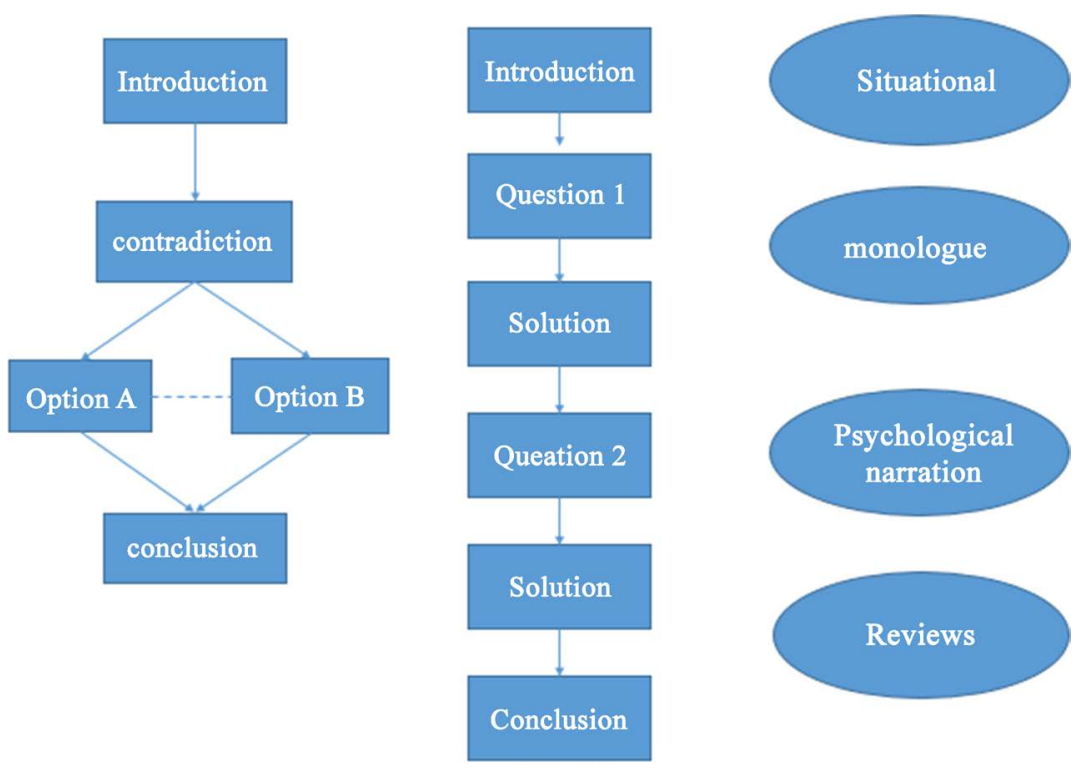

Figure 3. Story structure.

Figure 2. Firstly, the curriculum is introduced, and the general description of the knowledge points to be learned is carried out. Secondly, the knowledge points are decomposed one by one, and finally the knowledge points are summarized and reviewed. Second, the story structure, is shown in Figure 3. First, the course is introduced first, and then conflicts are raised. With regard to conflicts, there will be options A, B, C, etc., and then various knowledge points will be explained from different options, and finally a class summary. Second, the curriculum is introduced. And the problem is raised, and guide students to analyze the problem logically and come up with a solution. Then teacher raise the second problem from another angle In order to make students think with questions. This time teachers gradually guide the students to find a solution. Finally, the course makes a conclusion.

\section{Conclusion}

The development of science and technology is bound to drive the progress of society. In the era of integrated media, in order to improve teachers' information 
literacy and promote teacher professional development, classroom teaching will inevitably change with it, and online courses have also emerged. In online courses, teaching design and visual communication effects must be emphasized at the same time to achieve better classroom teaching effects. Therefore, teachers need to maintain a lifelong learning attitude at all times, and learn from and innovate teaching models that optimize classroom effects. At the same time, it is also necessary to design and produce online courses based on the learning characteristics and interests of students to maximize the advantages of online courses.

\section{Conflicts of Interest}

The authors declare no conflicts of interest regarding the publication of this paper.

\section{References}

Cen, J. L., \& Hu, T. S. (2013). Micro-Classes: A New Form of Digital Teaching Resources. Educational Information Technology, No. 4, 19-21.

Sang, X. M., \& Xie, Y. B. (2011). The 21st Century: Where to Go for Learning-An Outline of Green Learning Research. Open Education Research, 17, 10-16.

Song, Q. H. (2019). The Application of Micro-Classes in the Teaching of Information Technology in Junior High Schools. Quality Education in Western China, 5, 122. 